УДК 811.134.2'42

ББК 81.472.1-51

DOI: https://doi.org/10.17308/lic.2021.3/3574

\title{
В. А. ВИНОГРАДОВ И РАЗВИТИЕ СИСТЕМНОГО ПОДХОДА В ГРАММАТИКЕ
}

\author{
О. О. Борискина, В. Н. Картавцев
}

Воронежский государственный университет

\section{A. VINOGRADOV AND THE SYSTEMIC APPROACH TO GRAMMAR}

\author{
O. O. Boriskina, V. N. Kartavtsev \\ Voronezh State University
}

\begin{abstract}
Аннотация: в статье рассматривается вклад В. А. Виноградова в развитие системного подхода при исследовании типологических закономерностей грамматики в ее диалектической связи с лексикой. Информационной базой исследования послужили избранные труды В. А. Виноградова. Механизмы именной классификативности рассматриваются с позиций системного подхода как часть общей категориальной системы языка, состоящей из явной и скрытой грамматик. Особое внимание уделяется диалектичности и системности научного подхода В. А. Виноградова. Обосновывается его выдающаяся роль в обобщении и осмыслении всех видов проявления языковой классификативности для развития функционально ориентированной типологии лингвистических категорий.

Ключевые слова: системная лингвистика, общая категориальная система языка, явная и скрытая грамматика, именная классификативность, грамматическая типология языков, В. А. Виноградов как лингвист-теоретик.
\end{abstract}

\begin{abstract}
V. A. Vinogradov's contribution to the system approach development in the typological studies of grammar dialectically connected with lexis. Selected works by V. A. Vinogradov have been critically appraised. The mechanisms of noun classification devices are considered from the system approach point of view as a part of general categorial system of the language, which, in its turn, consists of overt and covert grammars. The particular focus is on dialectics and system orientation in V. A. Vinogradov's approach to linguistic categories. V. A. Vinogradov's contribution to the generalization and explanation of language classification phenomena and linguistic typology has proved outstanding.

Key words: system linguistics, linguistic categories, overt and covert, classification of nouns, grammatical typology, V. A. Vinogradov's contribution to linguistic theory.
\end{abstract}

\section{Введение}

Один из подходов к познанию мира еще во времена классической греческой философии оформился в концепцию диалектики, что в конечном итоге сводится к необходимости признать наличие между объектами реального мира бесконечного числа взаимосвязей, вариаций на фоне общего единства, бесконечную борьбу противоположных начал, дающую жизнь качественно новым состояниям вещей, постоянного движения и развития, распадающихся на бесконечное множество переходных состояний, границы которых, подобно смене кадров в фильме, невозможно уловить. Следствием принятия этой концепции становится отказ от попыток построить упрощенную механистическую модель мира, с одной стороны, и признание его бесконечной сложности - с другой. Уход от попыток разрешить некоторые неразрешимые противоречия, принятие антиномий и другие положения диалектики направляют активность познающего субъекта в конструктивное русло там, где раньше, казалось, была «непроходимая чаща». Диалектика как инструмент познания выстрадана и многократно проверена человечеством на протяжении последних 2500 лет; не удивительно, что философы

(C) Борискина О. О., Картавцев В. Н., 2021

Контент доступен под лицензией Creative Commons Attribution 4.0 License.

The content is available under Creative Commons Attribution 4.0 License. 
и ученые разных эпох, поднимавшие фундаментальные проблемы мироустройства, обращались к диалектике за разрешением реальных вопросов познания.

Одним из таких обращений стал поиск системного подхода к изучению языка. Уходящий своими корнями к трудам В. фон Гумбольдта данный подход является, по замечанию Г. П. Мельникова, реализацией синтеза идей целостности объекта (абсолютизируемых «холизмом») с «греческой» «последовательной» установкой в познании, направленной на изучение предмета во всем множестве его состояний и многообразии взаимосвязей $[1 ; 2]$.

Именно грамматика во всем многообразии внешних и внутренних взаимосвязей и исторических переходов и стала на определенном этапе предметом изучения В. А. Виноградова, выдающегося африканиста и теоретика языка. Для изучения грамматики в подобном русле, несомненно, требуется нащупать во всех сложных проявлениях закономерностей ее устройства и принципов функционирования некую объединительную логику, которая при этом не противоречила бы всей разности явлений языка, охватываемых грамматикой. Ведь историко-лингвистический контекст последних пятнадцати лет двадцатого и первых пятнадцати лет двадцать первого века времени, когда Виктором Алексеевичем были написаны главные работы по грамматической проблематике - был таким, что утверждалось, с одной стороны, широкое (или расширительное) понятие грамматики, когда в нее стали включаться явления так называемой грамматической периферии (см. в этой связи работы А. В. Бондарко, Т. В. Булыгиной и А. Д. Шмелева, В. А. Плунгяна), а с другой - неуклонно возрастал интерес ученого сообщества к когнитивным аспектам языковой семантики, к исследованию того, что $\Phi$. де Соссюр называл «внешней лингвистикой», связей языка с этносом, его культурой и историей (см. труды Ю. С. Степанова, Е. С. Кубряковой, В. И. Карасика, Н. И. Толстого, А. П. Бабушкина).

Естественно, оформление найденного В. А. Виноградовым объединительного начала произошло не сразу. Начинал В. А. Виноградов как фонолог. Но избранный им предмет исследования - сингармонизм - оказался своего рода мостом, связывающим фонетику и грамматику и требующим от исследователя учета также и грамматической проблематики. Тут-то впервые и проявилось диалектическое мировоззрение В. А. Виноградова, основанное на принципе максимального учета богатства связей изучаемого объекта в соответствии с сущностью диалектики как «учения о всеобщей взаимосвязи», наиболее полно и явно сформулированной и представленной в философии Г. В. Ф. Гегеля. По образному выражению И. А. Бодуэна де Куртенэ, сингармонизм - это «ф о н е т и ч е с к и й ц е м ен т, связывающий... несколько слогов в одно целое, т. е. в слово как в синтаксическую единицу, состоящую из морфологических (формальных) частей. $<\ldots>$ гармония гласных соединяет в одно слово слоги не фонетические, но морфологические» [3, c. 103-104].

В 1990 г. выходит программная статья «Варьирование именных классификаций» [4], в которой В. А. Виноградов, взяв за основу решение частной типологической проблемы (комплексного описания разных типов именной классификативности - именных классов, классификаторов и грамматического рода), по сути, выстроил цепочку переходов от наименее грамматикализованных способов категоризации понятий в языке к формально-грамматическому выражению категориальных смыслов. При этом он вышел за традиционные границы грамматического в сферу лексической семантики и показал ранние стадии развития именной классификативности - эхоморфию, эхосемию и, наконец, эпидигматику - наименее «выраженный» способ отражения в языке категоризации понятий. Так В. А. Виноградов одновременно утверждал необходимость комплексного подхода к типологическому изучению грамматических категорий, сочетающего диахронический анализ с синхронно-типологическим, и проводил, как он сам писал, «разведку левого края» в область неграмматикализованного, в сферу «зачаточных» состояний развития грамматических категорий [4, с. 305]. При этом читателя статьи не оставляет впечатление, что, говоря о категориях лексики и грамматики, автор никогда не упускает из виду факт, что любой язык с его конкретным типом и определенной стадией исторического развития не только используется, но и стихийно создается говорящим на нем народом, с характерными для него особенностями познания мира. Поражает и широта цитируемой и упоминаемой в статье лингвистической литературы. Складывается убеждение, что автор прочно связал всю предшествующую лингвистическую традицию с новым подходом, одновременно широким - в плане охвата языковых явлений и состояний и глубоким - в плане поиска объяснения наблюдаемых языковых закономерностей.

Уже в гораздо более поздних статьях - «Когнитивная категоризация мира и грамматика» и «Категориальность в языке: когнитивно-грамматический аспект» - В. А. Виноградов формулирует то, что составило суть его подхода к описанию грамматического и позволило столь полно и системно описывать именную классификативность, а именно: грамматика есть часть общей категориальной системы языка.

При таком подходе исходным пунктом описания языка становится категория - понятие, в котором нейтрализуются такие фундаментальные противоположности, как лексика и грамматика, форма и содержание, а также синхрония и диахрония, если мы 
обратимся к хронотопным условиям существования языка.

Категорию автор рассматривает как способ существования и представления языковых единиц. Соответственно, он обращается и к понятию категориальности - онтологической членимости языка и модусу познания мира по Аристотелю (последнее подчеркивает сам автор, что дает нам повод еще раз отметить общеметодологическую преемственность системного подхода по отношению к древнегреческой философской традиции).

В духе диалектики и одновременно в рамках гумбольдтианской традиции автор рассматривает речь как непрерывный процесс порождения текста через функционирование языка, изменяющегося и преобразующегося в ходе этого процесса. Переосмысляя такой подход в терминах современной лингвистики, В. А. Виноградов пишет о дискурсивном взаимодействии языковых категорий.

Категориальная система языка в аспекте ее внутренних взаимосвязей рассматривается В. А. Виноградовым сквозь призму диалектики единства и многообразия. Как уже было сказано выше, автор исчисляет виды языковых категорий: лексические и грамматические (среди последних выделяются классифицирующие, деривационные и словоизменительные), формальные и содержательные. Однако важнейшей становится именно идея системного единства категорий различного типа. Прежде всего, речь идет о диалектике тождества и различия лексики и грамматики. И единицы лексического, и единицы грамматического уровня могут выражать один и тот же категориальный смысл, образуя во взаимодействии единое функционально-семантическое поле. Собственно грамматические категории формируют ядра соответствующих полей, будучи ядрами категориальной системы языка. Лексические категории оказываются на периферии данных полей. В свою очередь, и лексические, и грамматические категории обладают планом выражения и планом содержания. В грамматике эти две стороны знака представлены соответственно грамматическими правилами и грамматическими категориями. Последние представлены в языке классемами, дериватемами и граммемами элементами классифицирующих, деривационных и словоизменительных категорий [4]. Словоизменительные категории составляют по В. А. Виноградову ядро грамматики - ядро ядра категориальной системы языка. Лексические и грамматические категории, входя в состав функционально-семантических полей и будучи организованы в них по оси «ядро - периферия», выражают концептуальные поля (семантические категории, частично совпадающие с понятийными категориями О. Есперсена), на которых зиждется та самая основа основ - категориальная систе- ма языка. Понятие грамматической периферии в отечественной лингвистике глубоко изучено В. А. Плунгяном [5]. Поле одновременно есть и основа единства формы и содержания, поскольку оно является двусторонней сущностью в семиотическом плане.

Внимательный читатель не может не заметить соотносимости взглядов В. А. Виноградова с концепцией другого выдающегося представителя системной лингвистики - Ю. С. Степанова. В частности, лексические и собственно грамматические (в узком смысле) категории соотносятся Виктором Алексеевичем с двумя осями грамматической (в широком смысле слова) абстракции, которые, наряду с третьей (локацией) выделялись Ю. С. Степановым - номинацией (лексические категории) и предикацией (грамматические). Последнее соотнесение также служит свидетельством взаимодействия лексических и грамматических категорий как представителей разных полюсов оси абстракции.

В единстве В. А. Виноградов рассматривает и такие «традиционные» типы грамматических категорий, как классифицирующие и словоизменительные. Ученый отмечает, что данное разделение «отражает два когнитивных процесса категоризации мира» [4, c. 510]. Данный тезис автор подкрепляет примером зависимости наличия в языке словоизменительной категории (числа) от категории классифицирующей (рода).

Несомненно, особой заслугой Виктора Алексеевича Виноградова является последовательное рассмотрение единства языковых категорий различного уровня в рамках шкалы состояний. Автор детально разрабатывает шкалу грамматикализованности именной классификативности, в рамках которой не только объединяется лексическое и грамматическое, скрытое и явное, содержательное и формальное, но также дается возможность взглянуть на систему категорий языка одновременно и в синхроническом, и в диахроническом планах.

Каждое из приведенных выше противопоставлений заслуживает отдельного внимания.

Во-первых, шкала грамматикализованности векторная и разворачивается слева направо в направлении от лексической семантики к грамматической форме. Такие состояния, как эпидигматика, эхосемия, эхоморфия и классификаторы, относятся к сфере лексических категорий; именные классы и род - напротив, к грамматическим.

Во-вторых, скрытая категориальность на векторе состояний В. А. Виноградова как бы опоясывает явную. Действительно, начальное и конечное состояния шкалы относятся к скрытой категориальности, в то время как ее внутренние состояния представляют явные категории - лексическую (классификаторы) и грамматическую (именные классы). 
В-третьих, при анализе отношения содержания к форме автор оперирует понятиями формальной прозрачности и затемненности воплощения. Формальная затемненность наблюдается в тех случаях, когда элементы категориальной системы языка существуют только в виде сем, как, например, в эпидигматике. При формальной прозрачности, напротив, элементы категорий проявляются в синтагматической цепи в виде морфем и слов, т. е. двусторонних сущностей знаковой природы, например, классификаторов.

Что же касается комплексного подхода к синхроническому и генетическому анализу, то для обоснования его актуальности автор проводит обзор широкого круга лингвистической литературы типологического и исторического характера. В результате показано развитие лингвистики в направлении соединения сравнительно-исторического и типологического подходов, а также круг проблем исторической типологии как части общей типологии. При этом становится естественной и понятной логика соединения идеи вектора (движение во времени и пространстве) и идеи шкалы (оценка синхронных состояний существующих систем).

Шкала грамматикализованности В. А. Виноградова представляет особенную ценность не только в плане ее использования в ходе типологических изысканий (см., например, [6]). Несомненна и ее общеязыковедческая ценность. Во-первых, в ней признанная и популярная ныне идея «укрупнения грамматики» (термин Ю. С. Степанова [7]) облекается в одежду точности и проверяемости - этих двух слагаемых «непререкаемого кредо лингвистики», сформулированного в свое время Е. В. Падучевой [8, с. 538]. Во-вторых, в ней прослеживается тенденция к построению - хотя бы на материале части языковой системы - так называемой «почему-лингвистики» (термин А. Е. Кибрика [9]), когда языковые феномены не только описываются в плане их устройства и функционирования, но через глубинное единство разрозненных, на первый взгляд, языковых фактов (таких, например, как лексические значения и род имен существительных) показана логика развития языка. Построение общетеоретических моделей на материале частных «кусочков» языковой системы стало хорошей практикой в лингвистике. Достаточно вспомнить роль изучения аспектологии в понимании общетеоретических проблем языка (см. работу А. М. Ломова [10]), а также фундаментальный труд Ю. П. Князева [11], поставившего как раз такую цель - «совместить в описании фрагмента русской грамматики эксплицитность основных положений с типологической достоверностью выводов и требуемым лексической семантикой (и когнитивной, и традиционной) установлением связей между значениями языковых единиц» [12, с. 8].
Таким образом, в плане объяснительной силы для решения задач общего языкознания данная шкала открывает широкие возможности для различных интерпретаций и моделей. В качестве частного примера подобного моделирования можно привести концепцию и методологию изучения скрытой категориальности в языке, оформленных в разработках Воронежской лексико-типологической группы (А. А. Кретов, О. О. Борискина, О. В. Донина, О. А. Голикова, О. Ф. Задобривская, В. Н. Картавцев), Идеи В. А. Виноградова легли в основу изучения именной и глагольной категориальности в языке, а также в практику выявления и описания скрытых и смешанных категорий в языках мира [13-19].

Обращение к «шкале В. А. Виноградова» позволяет глубже прояснить суть оппозиции «явное - скрытое» и избежать возможного отождествления лексического компонента функционально-семантического поля и скрытого класса языковых единиц. Ведь по В. А. Виноградову граница между лексическим и грамматическим (а на его шкале это граница между классификаторами и именными классами) не тождественна границе между скрытым и явным (граница между эхоморфией и классификаторами) [4].

Кроме того, через понятие грамматикализации мы выходим и в сферу внешних взаимосвязей категориальной системы языка, прежде всего, с говорящими на нем людьми, а точнее - их деятельностью в социуме. И данная сфера также не ускользает от внимания В. А. Виноградова, а напротив, рассматривается им в органической связи с традиционным, сугубо лингвистическим анализом языковых категорий. Данная связь вытекает из уже упоминавшегося нами понимания В. А. Виноградовым языка как сущности, которая «строится на дискурсивном взаимодействии... категорий» [4, с. 520], что наиболее четко оформилось в его поздних работах, посвященных связи когнитивных процессов и языковой категориальности. Так, исследователь приходит к выводу, что увеличение степени грамматикализации означает снижение дискурсивно-прагматического контроля над определенными категориальными смыслами со стороны пользователей языка, что связано с попаданием данных смыслов в сферу обязательного в языке. В этой связи любопытно сравнение Виктора Алексеевича: «Приобретение категорией статуса грамматической перемещает ее в ядро категориальной системы языка, охватывающее те семантические компоненты концептов, которые выводятся из-под сознательного контроля говорящего при оперировании ими в дискурсе, словно когнитивный императив ставит защиту над опорными смыслами языковой картины мира» $[4$, с. 510$]$.

В контексте обращения к дискурсивно-когнитивной стороне языковых явлений органично выглядит 
и обращение В. А. Виноградова к вопросам связи языка и культуры.

Действительно, как представитель системного подхода к изучению языка Виктор Алексеевич не мог оставить в стороне вопросы культурной среды, в которой существует и функционирует языковая система. Ученого занимают вопросы предмета лингвокультурологии, соотношения языка и культуры. Особенное внимание автор уделяет анализу системы базисных концептов, снова сближаясь в этом отношении с идеями Ю. С. Степанова. Весьма интересны наблюдения В. А. Виноградова по поводу таких понятий, как ВОЙНА, ПОБЕДА, НАЧАЛО, КОНЕЦ. Однако основной детально разобранный автором культурный концепт - это БЛИЗНЕЦЫ. И здесь ученый выступает, кроме прочего, как африканист, проводя детальный лингвокультурологический анализ данного концепта и языках африканских народов.

\section{Заключение}

При всей размытости и трудной уловимости языковой семантики, отягощенной культурными особенностями разных, в том числе и редких, языковых сообществ Виктор Алексеевич Виноградов сохранил строгость описания, воспринятую, по справедливому замечанию К. Г. Красухина, «в лоне Московской фонологической школы» [20]. Мы бы добавили: сохранил строгость и системность, поскольку через различные работы Виктора Алексеевича, начиная с его кандидатской диссертации, проводится мысль о преемственности по отношению к идеям В. фон Гумбольдта. Эта преемственность выражается в системном подходе к языку. Подходе, который, при всей своей широкой приложимости к изучению совершенно разных явлений языка, в том числе и в рамках междисциплинарных исследований, несомненно, предполагает строгость описания объекта и исследовательских процедур. На наш взгляд, это сочетание строгости с системностью и позволило Виктору Алексеевичу совершить такое количество открытий в разных областях языкознания, в том числе и в такой сложной сфере, как грамматика.

\section{ЛИТЕРАТУРА}

1. Мельников Г. П. Системная типология языков : синтез морфологической классификации языков со стадиальной. М. : Изд-во РУДН, 2000. 90 с.

2. Мельников Г. П. Системная типология языков : принципы, методы, модели / РАН. Ин-т языкознания. М. : Наука, 2003. 395 с.

3. Бодуэн де Куртенэ И. А. Избранные труды по общему языкознанию : в 2 т. М. : Изд-во АН СССР, 1963. T. I. 384 c.
4. Виноградов В. А. Статьи по общему языкознанию, компаративистике, типологии / сост. и ред. К. Г. Красухин. 2-е изд. М. : ЯСК, 2019. 544 с.

5. Плунгян B. A. Грамматические категории, их аналоги и заместители : дис. ... д-ра филол. наук. М., 1998. $256 \mathrm{c}$.

6. Boriskina O. O. A Corpus-based Study of Noun Cryptotypes in English // Компьютерная лингвистика и интеллектуальные технологии : материалы ежегод. Междунар. конф. / ред. кол. : А. Е. Кибрик [и др.]. М., 2011. С. 135-145.

7. Степанов Ю. С. Методы и принципы современной лингвистики. М. : Наука, 1975. 312 с.

8. Падучева Е. В. Динамические модели в семантике лексики. М. : Языки славянской культуры, 2004. 608 с.

9. Кибрик A. Е. Очерки по общим и прикладным вопросам языкознания (универсальное, типовое и специфичное в языке). М. : Изд-во МГУ, 1992. 336 с.

10. Ломов А. М. Очерки по русской аспектологии. Воронеж : Изд-во Воронеж. ун-та, 1977. 140 с.

11. Князев Ю. П. Грамматическая семантика : русский язык в типологической перспективе. М. : Языки славянских культур, 2007. 704 с.

12. Князев Ю. П. Проблемы описания грамматической семантики : дис. ... д-ра филол. наук. СПб., 2005. 382 c.

13. Борискина О. О. Теория, методология и опыт познания скрытой категориальности языка : автореф. дис. ... д-ра филол. наук. Воронеж, 2011.

14. Борискина О. О., Голикова О. А. Именная классификативность и ее интерпретация в лингвистической теории // Вестник Воронеж. гос. ун-та. Сер.: Лингвистика и межкультурная коммуникация. 2017. № 1. C. $11-16$.

15. Донина О. В. Скрытая категоризация эмоций в вариантах языка : автореф. дис. ... канд. филол. наук. Воронеж, 2017.

16. Кретов А. А., Борискина О. О., Донина О. В. Скрытые категории в исследованиях Воронежской лексико-типологической школы // Языковые категории и единицы : синтагматический аспект : материалы XII Междунар. науч. конф., посвящ. 65-летию кафедры русского языка. Воронеж, 2017. С. 267-270.

17. Голикова О. А. Именная классификативность в языке : криптокласс «Res Planae» : автореф. дис. ... канд. филол. наук. Воронеж, 2018.

18. Задобривская О. Ф. Эмоции как «вместилище» в вариантах английского языка : автореф. дис. ... канд. филол. наук. Воронеж, 2019.

19. Картавцев $B$. H. Реципрок как категория явной и скрытой грамматики : автореф. дис. ... канд. филол. наук. Воронеж, 2020.

20. Красухин К. Г. Предисловие // Виноградов В. А. Статьи по общему языкознанию, компаративистике, типологии / сост. и ред. К. Г. Красухин. 2-е изд. М. : ЯСК, 2019. C. 7-12. 


\section{REFERENCES}

1. Mel'nikov G. P. Sistemnaya tipologiya yazykov: sintez morfologicheskoj klassifikatsii yazykov so stadial'noj [System linguistic typology: synthesis of morphological and stadial linguistic classifications]. M.: Publ. RUDN, 2000. $90 \mathrm{p}$.

2. Mel'nikov G. P. Sistemnaya tipologiya yazykov: printsipy, metody, modeli [System linguistic typology: principles, methods, models]. RAN. Institute of Linguistics. M. Nauka, 2003. 395 p.

3. Boduen de Kurtene I. A. Izbrannye trudy po obshhemu yazykoznaniyu [Selected works on general linguistics]: in 2 v. M. : Publ. AN SSSR, 1963. T. 1. 384 p.

4. Vinogradov V. A. Stat'i po obshhemu yazykoznaniyu, komparativistike, tipologii [Articles on general, comparative and typological linguistics]. $2^{\text {nd }}$ edition. M.: YASK Publishing House, 2019. 544 p.

5. Plungyan V. A. Grammaticheskie kategorii, ikh analogi i zamestiteli [Grammatical Categories, their Analogues and Substitutes]. Doctoral Dissertation. Moscow, 1998. $256 \mathrm{p}$.

6. Boriskina O. O. A Corpus-based Study of Noun Cryptotypes in English. In: Komp'yuternaya lingvistika $i$ intellektual'nye tekhnologii. Materialy ezhegodnoj Mezhdunarodnoj konferentsii. Edited by: A. E. Kibrik et al. M., 2011. Pp. 135-145.

7. Stepanov Yu. S. Metody i printsipy sovremennoj lingvistiki [Methods and principles of modern linguistics]. M.: Nauka, 1975. 312 p.

8. Paducheva E. V. Dinamicheskie modeli v semantike leksiki [Dynamic models in lexical semantics]. M.: Yazyki slavyanskoj kul'tury Publ., 2004. 608 p.

9. Kibrik A. E. Ocherki po obshhim i prikladnym voprosam yazykoznaniya (universal'noe, tipovoe i spetsifichnoe $v$ yazyke) [Essays on general and applied linguistic issues (universal, typical and specific in the language)]. M.: Publ. MGU, 1992. 336 p.

10. Lomov A. M. Ocherki po russkoj aspektologii [Essay on Russian aspectology]. Voronezh: Publ. VGU, 1977. $140 \mathrm{p}$.

11. Knyazev Yu. P. Grammaticheskaia semantika: Russkii Yazyk v tipologicheskoi perspective [Grammatical Seman-

Воронежский государственный университет Борискина О. О., доктор филологических наук, декан факультета романо-германской филологии

E-mail: boriskinatipl@mail.ru

Картавцев В. Н., кандидат филологических наук, преподаватель кафедры английского языка гуманитарных факультетов

E-mail: kartavtsev-study-2012@yandex.ru

Поступила в редакциюю 20 мая 2021 г.

Принята к публикаџии 15 июня 20212. tics: the Russian Language in Typological Perspective]. Moscow: Yazyki Slavyanskikh Kul tur Publ., 2007. 704 p.

12. Knyazev Yu. P. Problemy opisaniya grammaticheskoj semantiki [Problems of grammatical semantics description]. Doktoral Dissertation. Saint-Petersburg, 2005. 382 p.

13. Boriskina O. O. Teoriya, metodologiya i opyt poznaniya skrytoj kategorial'nosti yazyka [Theory, methodology and cognition experience of covert linguistic categories]. Doktoral Dissertation Abstract. Voronezh, 2011.

14. Boriskina O. O., Golikova O. A. Imennaya klassifikativnost' i ee interpretatsiya $v$ lingvisticheskoj teorii [Noun classification devices and their interpretation in linguistic theory]. In: Vestnik VGU: Lingvistika i mezhkul'turnaya kommunikatsiya. 2017. No. 1. Pp. 11-16.

15. Donina O. V. Skrytaia kategorizatsia emotsii v variantakh iazyka [Covert Categorization of Emotions in Variants of the Language]. PhD Dissertation Abstract. Voronezh, 2017.

16. Kretov A. A., Boriskina O. O., Donina O. V. Skrytye kategorii v issledovaniyakh Voronezhskoj leksiko-tipologicheskoj shkoly [Covert categories in the research of the Voronezh Lexical Typology school]. In: Yazykovye kategorii i edinitsy: sintagmaticheskij aspekt. Materialy XII Mezhdunarodnoj nauchnoj konferentsii, posvyashhennoj 65-letiyu kafedry russkogo yazyka. Voronezh, 2017. Pp. 267-270.

17. Golikova O. A. Imennaia klassifikativnost'v iazyke: kriptoklass "Res Planae" [Nominative Classification in the Language: the Cryptotype "Res Planae"]. PhD Dissertation Abstract. Voronezh, 2018.

18. Zadobrivskaya O. F. Emotsii kak «vmestilishhe» v variantakh anglijskogo yazyka [Emotions as "containers" in the English language varieties]. PhD Dissertation Abstract. Voronezh, 2019.

19. Kartavtsev V. N. Retsiprok kak kategoriya yavnoj i skrytoj grammatiki [Reciprocity as an overt and covert grammatical category]. PhD Dissertation Abstract. Voronezh, 2020.

20. Krasukhin K. G. Predislovie [Introduction]. In: Vinogradov V. A. Stat'i po obshhemu yazykoznaniyu, komparativistike, tipologii. $2^{\text {nd }}$ edition. M.: YASK Publishing House, 2019.

Voronezh State University

Boriskina O. O., Doctor of Philology, Dean of Faculty of Romance and Germanic Philology

E-mail: boriskinatipl@mail.ru

Kartavtsev V. N., Candidate of Philology, Lecturer of the English Language for Humanities Department

E-mail: kartavtsev-study-2012@yandex.ru

Received: 20 May 2021

Accepted: 15 June 2021 


\section{Для цитирования:}

Борискина О. О., Картавцев В. Н. В. А. Виноградов и развитие системного подхода в грамматике // Вестник Воронежского государственного университета. Серия: Лингвистика и межкультурная коммуникация. 2021. № 3. C. 15-21. DOI: https://doi.org/10.17308/lic.2021.3/3574

\section{For citation:}

Boriskina O. O., Kartavtsev V. N. V. A. Vinogradov and the systemic approach to grammar. Proceedings of the Voronezh State University. Series: Linguistics and Intercultural Communication. 2021. No. 3. Pp. 15-21. DOI: https://doi.org/10.17308/lic.2021.3/3574 